\title{
Effect of Self-ligating on Bone Density and Root Surface in Maxilla and Mandible
}

\author{
Ashraf A. Shouman ${ }^{(1)}$, Mai S. Attia ${ }^{(2)}$, Samir A. Ibrahim ${ }^{(3)}$, Effat A. Abbas ${ }^{(4)}$, Osama A. Elshal ${ }^{(5)}$ \\ and Mohamed A. Ahmed ${ }^{(6)}$
}

Codex : 01/1801

azhardentj@azhar.edu.eg

http://adjg.journals.ekb.eg

\section{KEYWORDS}

Self-ligating, Damon, bone

density, root resorption.

\begin{abstract}
Objective: This study was designed to evaluate radiographically the effect of passive self-ligating bracket on root surface and bone density in both arches. Patients, materials and methods: The present study was conducted on 20 patients which were divided into two groups; the first group includes 10 adolescent patients aged 13-16 years old and the second group includes 10 adult patients aged 18-21 years old. For each arch of the individuals participating; a quadrant was bonded with passive self-ligating brackets and the other quadrant within the same arch was bonded by conventional brackets. Standardized reproducible digital panoramic radiographs for each patient were evaluated preoperatively (T0), 6 months (T1) and 1 year (T2) after beginning the orthodontic treatment. The four permanent canines were evaluated regarding the root length and bone density. An indirect digital image radiographic system was followed in this study to obtain and evaluate bone density and degree of root resorption. Results: There was no statistical significant difference in bone density and root resorption changes of the maxillary and the mandibular arches between both age groups. Conclusions: Passive self-ligating brackets tend to have the same effect on the bone density and root surface of both the maxilla and the mandible.
\end{abstract}

\section{INTRODUCTION}

Self-ligating brackets are said to decrease the chair-side time in addition to decreasing the number of recall visits and even the whole

1. Assistant Researcher of Orthodontics, Orthodontic and Pediatric Department, Oral and Dental Research Division, National Research Centre.

2. Associate Professor of Oral Medicine, Periodontology, Diagnosis and Radiology, Faculty of Dental Medicine for Girls, Al-Azhar University.

3. Professor and Chairman of Orthodontic Department, Faculty of Dental Medicine for Girls, Al-Azhar University.

4. Professor of Oral Pathology, Basic Dental Science Department, Oral and Dental Research Division, National Research Centre.

5. Professor of Oral Medicine, Vice Dean of Graduate Studies and Research Affair, Faculty of Dental Medicine, Faculty of Dental Medicine for Girls, Al-Azhar University.

6. Professor and Chairman of Orthodontics and Pediatric Dentistry Department, Orthodontics and Pediatric Dentistry Department, Oral and Dental Research Division, National Research Centre. 
treatment period. There were also claims about having less friction between the self-ligating bracket when compared with conventional bracket. The high cost of the self-ligating brackets in relation to the conventional ones which may reach several times of the conventional brackets made the researchers and the orthodontists think about the efficiency of the system. Apical root resorption is undesirable and inevitable sequelae of orthodontic tooth movement. It's well known that any orthodontic movement to the tooth causes apical root resorption and ceases whenever those forces are stopped. The degree of root resorption ranges from mild just blunting of the root apex to severe that is more than third of the root. Bone density is known to decrease during orthodontic tooth movement as the new bone formed is of relatively lower mineralization. It is a key factor for seeking long term stability decreasing the incidence of relapse of treated malocclusions. Passive self-ligating brackets were compared with other type of brackets and systems in many studies ${ }^{(1-13)}$. Different types of forces

Paper extracted from Doctor thesis entitled "Effect of Self versus Conventionally Ligating Orthodontic Brackets on Root Surface and Bone Density" and magnitudes were compared in the literature $^{(14-26)}$ to decrease the amount of root resorption. Apical root resorption was compared ${ }^{(27,28)}$ in vital versus endodontically treated teeth after orthodontic treatment. Also, the extent of external root resorption was compared in asthmatic patients versus medically free patients after fixed orthodontic treatment ${ }^{(29)}$. The incidence and severity of apical root resorption during orthodontic treatment with aligners were investigated ${ }^{(30)}$. Different treatment techniques and brackets were also compared regarding root resorption ${ }^{(31-38)}$. Therefore, the aim of the present study was to compare radiographically between the effect of passive self-ligating and conventionally ligating bracket regarding root surface and bone density in both arches in two different age groups.

\section{PATIENTS, MATERIALS AND METHODS}

The present study was conducted on 20 patients according to sample size power test aged 13-21 years old. These patients were selected from those attending the outpatient clinic, Department of Orthodontics, Faculty of Dental Medicine for Girls, Al Azhar University (Girls' Branch). The sample was divided into two groups; the first group includes 10 adolescent patients aged 13-16 years old and the second group includes 10 adult patients aged 18-21 years old.

\section{Criteria of selection of the participants:}

1. No history of previous orthodontic treatment.

2. No history of previous teeth extractions with the exception of wisdom teeth.

3. Absence of any systemic disease that may affect bone.

4. No history of trauma.

5. No evidence of root resorption on the pretreatment panoramic radiographs.

6. Good oral hygiene.

7. Highly motivation and cooperation.

8. Class I Angle malocclusion.

9. The treatment plan requires extraction of the premolars.

Ethical approval was obtained from the Medical Research Ethics Committee of National Research Centre.

For each arch of the individuals participating; a quadrant was bonded with passive self-ligating brackets (Damon 3, ORMCO) and the other quadrant within the same arch was bonded by conventional brackets (Mini 2000, ORMCO) (split-mouth study). And it was alternated with the next patient.

For the first 6 months of treatment, leveling and alignment was performed by 0.013 ", 0.016 " and 0.018" Damon $\mathrm{Cu}-\mathrm{Ni}$-Ti wires, they were replaced every 2 months with the same sequence. In the next 6 months 0.018 " round stainless steel wire was used for retraction of the permanent canines. 
Standardized reproducible digital panoramic radiographs for each patient were evaluated preoperatively (T0), 6 months (T1) and 1 year (T2) after beginning the orthodontic treatment. The four permanent canines were evaluated regarding the root length and bone density $(13,23,33$ or 43$)$ and the type of the bracket used (conventional or selfligating). An indirect digital image radiographic system, the DBSWin software, which is a part of the recently introduced Vista Scan system, was followed in this study to obtain and evaluate bone density and degree of root resorption, using the image processing software.

For each patient, information including personal and medical history, in addition to the radiographic images, and all data were recorded and saved on the patient's card. The saved radiographic images for each patient were interpreted to record bone density and to calculate surface root resorption.

\section{a-Bone density-densitometric radiographic measurement.}

Linear density measurements were performed by drawing a line parallel to the root surface. The line extended from the apex of the alveolar crest to the level of the apex of the root. Two lines were drawn; one mesial to the root of the permanent canine and the other distal to it. The grey level along each line was recorded at the beginning of the line, at the middle, and at the end. The average of the six (three from the mesial line and three from the distal) was calculated to obtain the mean average grey level along this line this represents the alveolar bone density. These measurements were taken at the three mentioned time intervals.

\section{b- Root resorption-linear radiographic measurement}

The measurement of the root length was done by measuring the distance between the cementoenamel junction (as a reference point) to the apex of the root. A comparison between the linear measurements prior to treatment, 6 months and 1 year after beginning the orthodontic treatment were done to determine the extent of apical root resorption. The resorption was evaluated in term of millimeters and percentage.
The results were tabulated. Mean and standard deviation were calculated for each group. T-test was used to evaluate the statistical difference between the groups.

\section{RESULTS}

\section{Root length changes}

In the self-ligating adult group, the results of the study showed that there was no statistically significant difference root resorption in the maxillary and the mandibular arches with values $1.07 \pm 0.38$ $(5.60 \% \pm 1.58)$ and $0.86 \pm 0.28(5.25 \% \pm 1.59)$ respectively in the first six months and $1.04 \pm 0.42$ $(5.88 \% \pm 2.32)$ and $0.98 \pm 0.44(6.37 \% \pm 2.82)$ respectively in the next six months. (Table 1 and Figure 1).

Regarding the results of the self-ligating adolescent group, the maxillary and the mandibular arches showed resorption of $1.09 \pm 0.27(7.72 \% \pm 1.87)$ and $1.04 \pm 0.27(7.06 \% \pm 1.85)$ respectively in the first six months and $0.78 \pm 0.21(5.97 \% \pm 1.60)$ and $0.79 \pm 0.25(5.72 \% \pm 1.70)$ respectively in the next six months with no significant difference between them. (Table 2 and Figure 2).

\section{Bone density changes:}

Regarding the results of the self-ligating adult group, the maxillary and the mandibular arches showed bone density redutction of $2.86 \pm 1.21$ $(8.05 \% \pm 3.13)$ and $3.54 \pm 1.08(8.57 \% \pm 2.50)$ respectively in the first six months and $2.71 \pm 1.81(8.42 \%$ $\pm 5.43)$ and $2.13 \pm 0.98(5.54 \% \pm 2.07)$ respectively in the next six months with no significant difference between them. (Table 3 and Figure 3).

Concerning the self-ligating adolescent group, the results of the study showed that there was no statistically significant difference in bone density changes in the maxillary and the mandibular arches with values $3.07 \pm 1.13(8.18 \% \pm 2.56)$ and $2.92 \pm 1.49(8.48 \% \pm 4.78)$ respectively in the first six months and $2.17 \pm 1.61(6.35 \% \pm 4.87)$ and $1.57 \pm 1.17$ $(4.57 \% \pm 2.93)$ respectively in the next six months. (Table 4 and Figure 4). 
Table 1: Mean and standard deviations (SD) values of maxillary and mandibular root length changes within the Self-ligating group after 6 and 12 months in adults.

\begin{tabular}{|c|c|c|c|c|c|}
\hline \multirow{2}{*}{\multicolumn{2}{|c|}{ Self- Ligating }} & \multirow{3}{*}{$\begin{array}{c}\begin{array}{c}\text { Maxillary root } \\
\text { length }\end{array} \\
1.07 \pm 0.38\end{array}$} & \multirow{3}{*}{$\begin{array}{c}\begin{array}{c}\text { Mandibular root } \\
\text { length }\end{array} \\
0.86 \pm 0.28\end{array}$} & \multirow{2}{*}{\multicolumn{2}{|c|}{ Paired t-test }} \\
\hline & & & & & \\
\hline \multirow{2}{*}{ T0-T1 } & Mean \pm SD & & & \multirow{2}{*}{2.125} & \multirow{2}{*}{0.057} \\
\hline & Range & $0.60-2.00$ & $0.40-1.20$ & & \\
\hline \multirow{2}{*}{$\mathrm{T} 1-\mathrm{T} 2$} & Mean \pm SD & $1.04 \pm 0.42$ & $0.98 \pm 0.44$ & \multirow{2}{*}{0.490} & \multirow{2}{*}{0.634} \\
\hline & Range & $0.50-1.70$ & $0.40-1.70$ & & \\
\hline \multirow{2}{*}{ T0-T1\% } & Mean \pm SD & $5.60 \pm 1.58$ & $5.25 \pm 1.59$ & \multirow{2}{*}{0.726} & \multirow{2}{*}{0.483} \\
\hline & Range & $3.70-9.26$ & $2.45-6.98$ & & \\
\hline \multirow{2}{*}{$\mathrm{T} 1-\mathrm{T} 2 \%$} & Mean \pm SD & $5.88 \pm 2.32$ & $6.37 \pm 2.82$ & \multirow{2}{*}{0.658} & \multirow{2}{*}{0.524} \\
\hline & Range & $2.72-9.34$ & $2.63-10.97$ & & \\
\hline
\end{tabular}

Table 2: Mean and standard deviations (SD) values of the maxillary \& mandibular root length within the Self-ligating group after 6 \& 12 months in adolescents.

\begin{tabular}{|c|c|c|c|c|c|}
\hline \multirow{2}{*}{\multicolumn{2}{|c|}{ Self-Ligating }} & \multirow{3}{*}{$\begin{array}{c}\begin{array}{c}\text { Maxillary root } \\
\text { length }\end{array} \\
1.09 \pm 0.27 \\
\end{array}$} & \multirow{3}{*}{$\begin{array}{c}\begin{array}{c}\text { Mandibular } \\
\text { root length }\end{array} \\
1.04 \pm 0.27 \\
\end{array}$} & \multicolumn{2}{|c|}{ Paired t-test } \\
\hline & & & & $\mathbf{t}$ & p-value \\
\hline \multirow{2}{*}{$\mathrm{T} 0-\mathrm{T} 1$} & Mean \pm SD & & & \multirow{2}{*}{0.413} & \multirow{2}{*}{0.692} \\
\hline & Range & $0.70-1.40$ & $0.70-1.40$ & & \\
\hline \multirow{2}{*}{$\mathrm{T} 1-\mathrm{T} 2$} & Mean \pm SD & $0.78 \pm 0.21$ & $0.79 \pm 0.25$ & \multirow{2}{*}{-0.131} & \multirow{2}{*}{0.899} \\
\hline & Range & $0.40-1.00$ & $0.30-1.10$ & & \\
\hline \multirow{2}{*}{ T0-T1 \% } & Mean \pm SD & $7.72 \pm 1.87$ & $7.06 \pm 1.85$ & \multirow{2}{*}{0.725} & \multirow{2}{*}{0.492} \\
\hline & Range & $5.26-9.93$ & $4.86-9.93$ & & \\
\hline \multirow{2}{*}{ T1-T2 \% } & Mean \pm SD & $5.97 \pm 1.60$ & $5.72 \pm 1.70$ & \multirow{2}{*}{0.340} & \multirow{2}{*}{0.744} \\
\hline & Range & $3.13-7.87$ & $2.36-7.69$ & & \\
\hline
\end{tabular}

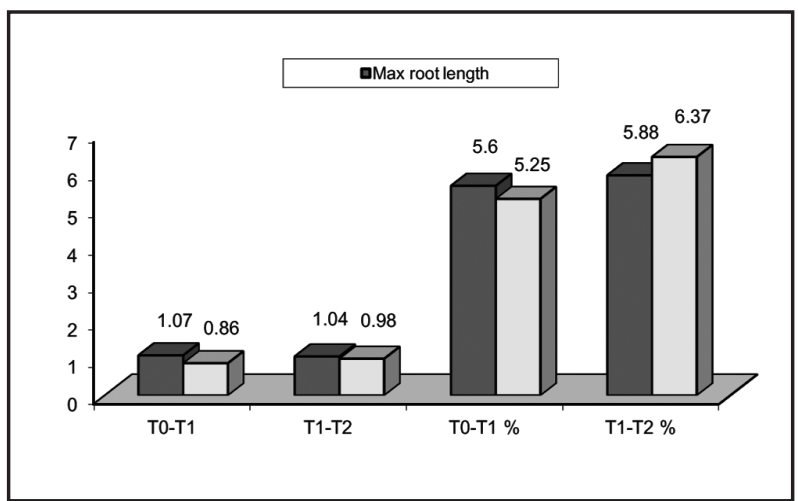

Fig. (1) Bar chart for comparing the maxillary and mandibular root length changes associated with Conventional ligating group after 6 and 12 months in $\mathrm{mm}$ and percentage in adults

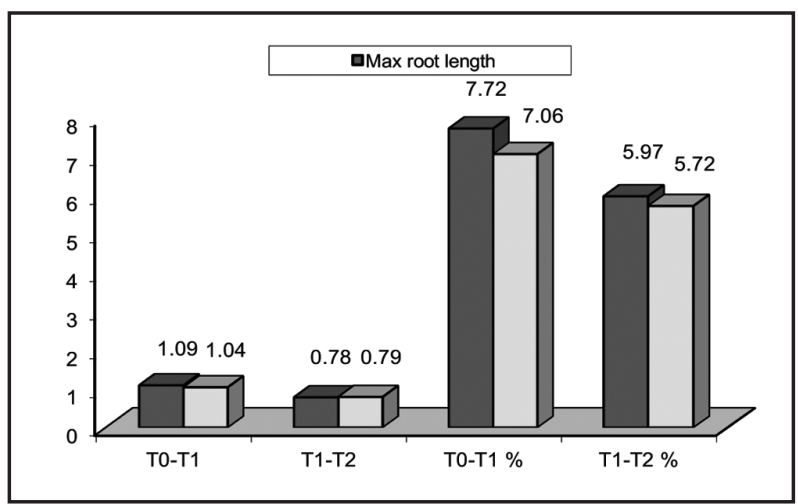

Fig. (2) Bar chart for the changes in the maxillary and mandibular root length in the Self-ligating group after 6 and 12 months in mm and percentage in adolescents. 
Table 3: Mean and standard deviations (SD) values of the maxillary and mandibular bone density within the self-ligating group after 6 and 12 months in adults.

\begin{tabular}{|c|c|c|c|c|c|}
\hline \multirow{2}{*}{\multicolumn{2}{|c|}{ Self Ligating }} & \multirow{3}{*}{$\begin{array}{c}\begin{array}{c}\text { Maxillary root } \\
\text { length }\end{array} \\
2.86 \pm 1.21\end{array}$} & \multirow{3}{*}{$\begin{array}{c}\begin{array}{c}\text { Mandibular root } \\
\text { length }\end{array} \\
3.54 \pm 1.08\end{array}$} & \multicolumn{2}{|c|}{ Paired t-test } \\
\hline & & & & & \\
\hline \multirow{2}{*}{ T0-T1 } & Mean \pm SD & & & \multirow{2}{*}{-1.444} & \multirow{2}{*}{0.177} \\
\hline & Range & $0.34-4.35$ & $1.88-5.20$ & & \\
\hline \multirow{2}{*}{ T1-T2 } & Mean \pm SD & $2.71 \pm 1.81$ & $2.13 \pm 0.98$ & \multirow{2}{*}{1.066} & \multirow{2}{*}{0.309} \\
\hline & Range & $0.42-5.82$ & $0.82-3.77$ & & \\
\hline \multirow{2}{*}{ T0-T1 \% } & Mean \pm SD & $8.05 \pm 3.13$ & $8.57 \pm 2.50$ & \multirow{2}{*}{-0.642} & \multirow{2}{*}{0.534} \\
\hline & Range & $1.20-12.71$ & $5.12-14.57$ & & \\
\hline \multirow{2}{*}{$\mathrm{T} 1-\mathrm{T} 2 \%$} & Mean \pm SD & $8.42 \pm 5.43$ & $5.54 \pm 2.07$ & \multirow{2}{*}{1.842} & \multirow{2}{*}{0.093} \\
\hline & Range & $1.44-17.60$ & $2.82-8.22$ & & \\
\hline
\end{tabular}

Table 4: Mean and standard deviations (SD) values of the maxillary and mandibular bone density within the self-ligating group after 6 and 12 months in adolescents.

\begin{tabular}{|c|c|c|c|c|c|}
\hline \multirow{2}{*}{\multicolumn{2}{|c|}{ Self Ligating }} & \multirow{3}{*}{$\begin{array}{c}\begin{array}{c}\text { Maxillary bone } \\
\text { density }\end{array} \\
3.07 \pm 1.13 \\
\end{array}$} & \multirow{3}{*}{$\begin{array}{c}\begin{array}{c}\text { Mandibular bone } \\
\text { density }\end{array} \\
2.92 \pm 1.49\end{array}$} & \multicolumn{2}{|c|}{ Paired t-test } \\
\hline & & & & \multirow{3}{*}{$\begin{array}{c}\text { p-value } \\
0.252\end{array}$} & \multirow{3}{*}{0.808} \\
\hline \multirow{2}{*}{ T0-T1 } & Mean \pm SD & & & & \\
\hline & Range & $2.03-5.65$ & $0.46-4.64$ & & \\
\hline \multirow{2}{*}{$\mathrm{T} 1-\mathrm{T} 2$} & Mean \pm SD & $2.17 \pm 1.61$ & $1.57 \pm 1.17$ & \multirow{2}{*}{1.902} & \multirow{2}{*}{0.099} \\
\hline & Range & $0.34-5.36$ & $0.46-4.21$ & & \\
\hline \multirow{2}{*}{ T0-T1 \% } & Mean \pm SD & $8.18 \pm 2.56$ & $8.48 \pm 4.78$ & \multirow{2}{*}{-0.176} & \multirow{2}{*}{0.865} \\
\hline & Range & $5.96-13.85$ & $1.18-14.09$ & & \\
\hline \multirow{2}{*}{$\mathrm{T} 1-\mathrm{T} 2 \%$} & Mean \pm SD & $6.35 \pm 4.87$ & $4.57 \pm 2.93$ & \multirow{2}{*}{1.779} & \multirow{2}{*}{0.118} \\
\hline & Range & $1.06-16.27$ & $1.63-10.90$ & & \\
\hline
\end{tabular}

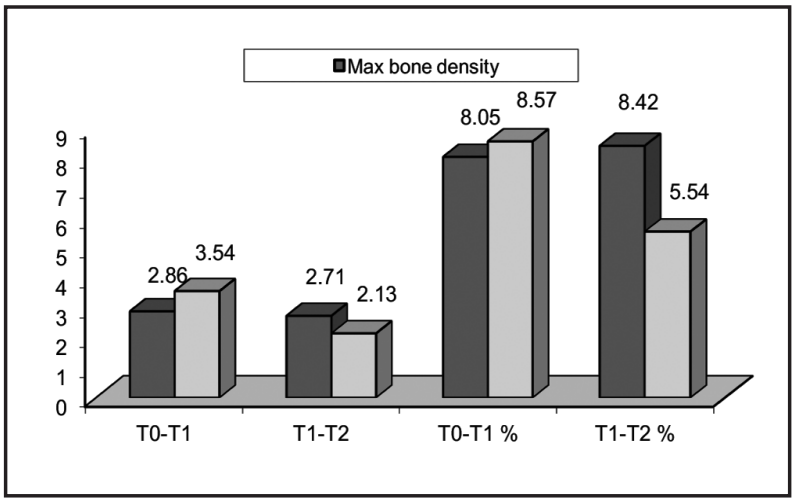

Fig. (3) Bar chart for comparing the changes between the maxillary and mandibular bone density within the selfligating group after 6 and 12 months in adults.

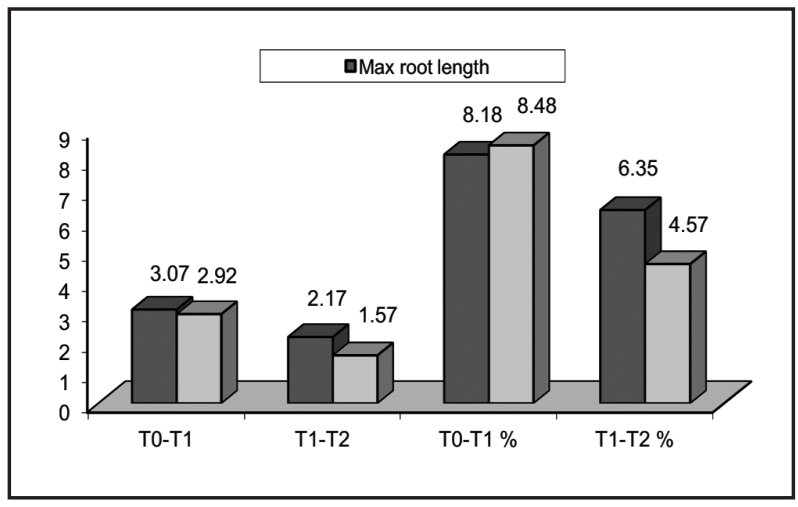

Fig. (4) Bar chart for comparing the changes between the maxillary and mandibular bone density within the selfligating group after 6 and 12 months in adolescents. 


\section{DISCUSSION}

The introduction of the self-ligating brackets in the last decades made them in the field of interest for the orthodontists and researchers to clarify the efficiency of that system of brackets and whether it is really beneficial to the orthodontist and the patient. In the present study two parameters were chosen to be compared between the standard Roth brackets which are the most popular type of brackets used in the market and the self-ligating brackets; they are root resorption and the bone density. Root resorption is the most common undesirable inevitable effect of orthodontic treatment and it was of prime interest for the researchers to figure out a way to decrease the amount of resorption. Many studies were performed to compare the effect of different techniques and systems on root resorption ${ }^{(31-38)}$. Other studies compared the effect of different types of forces applied to the tooth with the resulted root resorption ${ }^{(14-23)}$. Some studies correlated the root resorption occurring at the first stage of treatment with the rest of treatment, others highlighted the most common teeth to be affected with root resorption ${ }^{(27,28)}$. Even the studies went further to examine the effect of medically compromised conditions on root resorption ${ }^{(29)}$. Bone density in spite of its importance in the long term stability of orthodontic treatment, yet fewer studies were performed regarding this issue.

In the present study, digital panoramic radiographs were used for the evaluation of root resorption, split-mouth study was used to decrease the error resulting from the individual variation.

The results in adults showed that when comparing the maxillary root length changes with the mandibular one in both the self-ligating group and in the conventional one, it showed no statistically significant difference between the degrees of root resorption. And also, upon comparing the changes that occured in the bone density between the maxillary and the mandibular dental arches within the standard Roth group and the Damon group; there was no statistically significant difference between them.
In the adolescent group; the same finding was observed when comparing the maxillary root resorption with the mandibular one within the standard Roth group and also when comparing the maxillary root resorption with the mandibular within the Damon group. When comparing the bone density changes between the maxillary and the mandibular dental arches within the conventional group; the reduction in the mandibular bone density was significantly higher than in the maxillary arch. For the self-ligating group; there was no statistically significant difference between them.

\section{CONCLUSIONS}

Self-ligating brackets were found not to have better effect when used on the maxilla over the mandible or vice versa.

\section{REFERENCES}

1. Johansson $\mathrm{K}$, Lundstrom $\mathrm{F}$. Orthodontic treatment efficiency with self-ligating and conventional edgewise twin brackets: a prospective randomized clinical trial. Angle Orthod 2012;82:929-34.

2. Mezomo M, de Lima ES, de Menezes LM, Weissheimer A, Allgayer S. Maxillary canine retraction with self-ligating and conventional brackets. Angle Orthod 2011;81:292-7.

3. Burrow SJ. Canine retraction rate with self-ligating brackets vs conventional edgewise brackets. Angle Orthod 2010;80:438-45

4. Miles PG, Weyant RJ, Rustveld L. A clinical trial of Damon 2 vs conventional twin brackets during initial alignment. Angle Orthod 2006;76:480-5

5. Kaygisiz E, Uzuner FD, Yuksel S. Effects of self-ligating and conventional brackets on halitosis and periodontal conditions. Angle Orthod 2015;85:468-73.

6. Da Costa Monini A, Junior LG, Martins RP, Vianna AP. Canine retraction and anchorage loss: self-ligating versus conventional brackets in a randomized split-mouth study. Angle Orthod 2014;84:846-52.

7. Shook C, Kim SM, Burnheimer J. Maxillary arch width and buccal corridor changes with Damon and conventional brackets: A retrospective analysis. Angle Orthod 2016;86:655-60. 
8. Miles PG. Self-ligating vs conventional twin brackets during en-masse space closure with sliding mechanics. Am J Orthod Dentofac Orthop 2007;132:223-5.

9. DiBiase AT, Nasr IH, Scott P, Cobourne MT. Duration of treatment and occlusal outcome using Damon3 selfligated and conventional orthodontic bracket systems in extraction patients: a prospective randomized clinical trial. Am J Orthod Dentofac Orthop 2011;139:e111-6.

10. Pringle AM, Petrie A, Cunningham SJ, McKnight M. Prospective randomized clinical trial to compare pain levels associated with 2 orthodontic fixed bracket systems. Am J Orthod Dentofac Orthop 2009;136:160-7.

11. Pandis N, Polychronopoulou A, Eliades T. Self-ligating vs conventional brackets in the treatment of mandibular crowding: a prospective clinical trial of treatment duration and dental effects. Am J Orthod Dentofac Orthop 2007;132:208-15.

12. Fleming PS, Lee RT, Marinho V, Johal A. Comparison of maxillary arch dimensional changes with passive and active self-ligation and conventional brackets in the permanent dentition: a multicenter, randomized controlled trial. Am J Orthod Dentofac Orthop 2013;144:185-93.

13. Songra G, Clover M, Atack NE. Comparative assessment of alignment efficiency and space closure of active and passive self-ligating vs conventional appliances in adolescents: a single-center randomized controlled trial. Am J Orthod Dentofac Orthop 2014;145:569-78.

14. Owman-Moll P, Kurol J, Lundgren D. Continuous versus interrupted continuous orthodontic force related to early tooth movement and root resorption. Angle orthod 1995;65:395-401.

15. Paetyangkul A, Turk T, Elekdag-Turk S. Physical properties of root cementum: Part 16. Comparisons of root resorption and resorption craters after the application of light and heavy continuous and controlled orthodontic forces for 4, 8, and 12 weeks. Am J Orthod Dentofac Orthop 2011;139:279-84.

16. Cheng LL, Turk T, Elekdag-Turk S, Jones AS, Petocz P, Darendeliler MA. Physical properties of root cementum: Part 13. Repair of root resorption 4 and 8 weeks after the application of continuous light and heavy forces for 4 weeks: a microcomputed-tomography study. Am J Orthod Dentofac Orthop 2009;136:320 e321-310; discussion 320-321.

17. Ballard DJ, Jones AS, Petocz P, Darendeliler MA. Physical properties of root cementum: part 11. Continuous vs intermittent controlled orthodontic forces on root resorption. A microcomputed-tomography study. Am J Orthod Dentofac Orthop 2009;136:8 e1-8; discussion 8-9.

18. Chan E, Darendeliler MA. Physical properties of root cementum: Part 5. Volumetric analysis of root resorption craters after application of light and heavy orthodontic forces. Am J Orthod Dentofac Orthop 2005;127:186-95.

19. Chan E, Darendeliler MA. Physical properties of root cementum: part 7. Extent of root resorption under areas of compression and tension. Am J Orthod Dentofac Orthop 2006;129:504-10.

20. Harris DA, Jones AS, Darendeliler MA. Physical properties of root cementum: part 8. Volumetric analysis of root resorption craters after application of controlled intrusive light and heavy orthodontic forces: a microcomputed tomography scan study. Am J Orthod Dentofac Orthop 2006;130:639-47.

21. Wu AT, Turk T, Colak C. Physical properties of root cementum: Part 18. The extent of root resorption after the application of light and heavy controlled rotational orthodontic forces for 4 weeks: a microcomputed tomography study. Am J Orthod Dentofac Orthop 2011;139:e495-503.

22. Bartley N, Turk T, Colak C, et al. Physical properties of root cementum: Part 17. Root resorption after the application of 2.5 degrees and 15 degrees of buccal root torque for 4 weeks: a microcomputed tomography study. Am J Orthod Dentofac Orthop 2011;139:e353-60.

23. Paetyangkul A, Turk T, Elekdag-Turk S, Jones AS, Petocz P, Darendeliler MA. Physical properties of root cementum: part 14. The amount of root resorption after force application for 12 weeks on maxillary and mandibular premolars: a microcomputed-tomography study. Am J Orthod Dentofac Orthop 2009;136:492 e491-9; discussion 492-3.

24. Ho C, Turk T, Elekdag-Turk S. Physical properties of root cementum: Part 19. Comparison of the amounts of root resorption between the right and left first premolars after application of buccally directed heavy orthodontic tipping forces. Am J Orthod Dentofac Orthop 2011;140:e49-52.

25. Montenegro VC, Jones A, Petocz P, Gonzales C, Darendeliler MA. Physical properties of root cementum: Part 22. Root resorption after the application of light and heavy extrusive orthodontic forces: a microcomputed tomography study. Am J Orthod Dentofac Orthop 2012; 141:e1-9. 
26. King AD, Turk T, Colak C. Physical properties of root cementum: part 21. Extent of root resorption after the application of 2.5 degrees and 15 degrees tips for 4 weeks: a microcomputed tomography study. Am J Orthod Dentofac Orthop 2011;140:e299-305.

27. Castro I, Valladares-Neto J, Estrela C. Contribution of cone beam computed tomography to the detection of apical root resorption after orthodontic treatment in rootfilled and vital teeth. Angle orthod 2015;85:771-6.

28. Spurrier SW, Hall SH, Joondeph DR, Shapiro PA, Riedel RA. A comparison of apical root resorption during orthodontic treatment in endodontically treated and vital teeth. Am J Orthod Dentofac Orthop 1990;97:130-4.

29. McNab S, Battistutta D, Taverne A, Symons AL. External apical root resorption of posterior teeth in asthmatics after orthodontic treatment. Am J Orthod Dentofac Orthop 1999; 116:545-51.

30. Krieger E, Drechsler T, Schmidtmann I, Jacobs C, Haag $\mathrm{S}$, Wehrbein $\mathrm{H}$. Apical root resorption during orthodontic treatment with aligners? A retrospective radiometric study. Head \& face medicine 2013;9:21.

31. McNab S, Battistutta D, Taverne A, Symons AL. External apical root resorption following orthodontic treatment. Angle orthod 2000;70:227-32.

32. Leite V, Conti AC, Navarro R, Almeida M, OltramariNavarro P, Almeida R. Comparison of root resorption between self-ligating and conventional preadjusted brackets using cone beam computed tomography. Angle orthod 2012;82:1078-82.

33. Pandis N, Nasika M, Polychronopoulou A, Eliades T. External apical root resorption in patients treated with conventional and self-ligating brackets. Am J Orthod Dentofac Orthop 2008;134:646-51

34. Blake M, Woodside DG, Pharoah MJ. A radiographic comparison of apical root resorption after orthodontic treatment with the edgewise and Speed appliances. Am J Orthod Dentofac Orthop 1995;108:76-84.

35. Beck BW, Harris EF. Apical root resorption in orthodontically treated subjects: analysis of edgewise and light wire mechanics. Am J Orthod Dentofac Orthop 1994;105:350-61.

36. Janson GR, De Luca Canto G, Martins DR, Henriques JF, De Freitas MR. A radiographic comparison of apical root resorption after orthodontic treatment with 3 different fixed appliance techniques. Am J Orthod Dentofac Orthop 2000;118:262-73.

37. Handem RH, Janson G, Matias M. External root resorption with the self-ligating Damon system-a retrospective study. Prog Orthod 2016;17:20.

38. Mavragani M, Vergari A, Selliseth NJ, Boe OE, Wisth PL. A radiographic comparison of apical root resorption after orthodontic treatment with a standard edgewise and a straight-wire edgewise technique. Eur J Orthod 2000;22:665-74 